\title{
Antitumor Effect of Everolimus in Preclinical Models of High-Grade Gastroenteropancreatic Neuroendocrine Carcinomas
}

\author{
Julien Bollard ${ }^{a} \quad$ Christophe Couderc $^{a}$ Martine Blanc ${ }^{a} \quad$ Gilles Poncet $^{a}$ b \\ Florian Lepinasse $^{a, c}$ Valérie Hervieu ${ }^{a, c}$ Géraldine Gouysse ${ }^{c}$ \\ Carole Ferraro-Peyret $^{\mathrm{a}, \mathrm{c}}$ Noura Benslama ${ }^{\mathrm{a}, \mathrm{b}}$ Thomas Walter ${ }^{\mathrm{a}, \mathrm{b}}$ \\ Jean-Yves Scoazec ${ }^{a, c} \quad$ Colette Roche $^{a}$ \\ ${ }^{a}$ Endocrine Differentiation and Tumorigenesis Laboratory, Centre de Recherche en Cancérologie de Lyon,

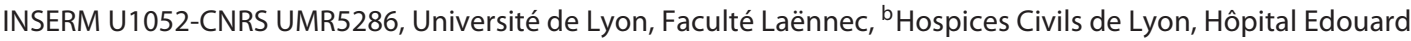 \\ Herriot, Fédération des Spécialités Digestives and ${ }^{\mathrm{C} H o s p i c e s ~ C i v i l s ~ d e ~ L y o n, ~ H o ̂ p i t a l ~ E d o u a r d ~ H e r r i o t, ~}$ \\ Service d'Anatomie Pathologique, Lyon, France
}

\section{Key Words}

Poorly differentiated neuroendocrine tumors - Preclinical models $\cdot$ Animal model $\cdot \mathrm{mTOR} \cdot$ Everolimus

\begin{abstract}
Background/Aims: While the range of therapeutic options for well-differentiated gastroenteropancreatic neuroendocrine tumors has recently increased with the emergence of targeted therapies, such as mTOR inhibitors, there is no recent progress in the treatment of poorly differentiated neuroendocrine carcinomas (PDNECs). Since PDNECs have been shown to strongly express mTOR pathway components, the aim of the present study was to assess the antitumor effect of the mTOR inhibitor everolimus in preclinical models of PDNECs. Methods: The expression of mTOR pathway components and their response to everolimus were assessed in two neuroendocrine cell lines: STC-1 and GluTag. A xenograft model of intrahepatic dissemination in the nude mouse, based on the intrasplenic injection of either STC-1 and GluTag tumor cells, was used. Animals were started on everolimus treatment 3 days after injection. The effects of treatment on tumor growth, proliferative capacities, apo-
\end{abstract}

\section{KARGER}

(C) 2013 S. Karger AG, Base

0028-3835/13/0974-0331\$38.00/0

E-Mail karger@karger.com

www.karger.com/nen ptosis and in situ expression of mTOR pathway components were assessed. Results: The expression of mTOR pathway components was comparable in STC-1 and GluTag cells and in human PDNECs and could be inhibited in vitro by everolimus. In vivo, the tumor volume of STC-1 and GluTag xenografts was significantly reduced in treated animals $(6.05 \pm$ $1.84 \%$ as compared to $21.76 \pm 3.88 \%$ in controls). Everolimus treatment also induced a significant decrease in Ki67 index and in the phosphorylation levels of the two major effectors of $\mathrm{mTOR}$, p70S6K and 4E-BP1. Conclusion: Our experimental data suggest that mTOR inhibition could be considered a therapeutic option for high-grade gastroenteropancreatic neuroendocrine tumors.

Copyright $\odot 2013$ S. Karger AG, Basel

\section{Introduction}

Gastroenteropancreatic neuroendocrine tumors (GEP NETs) are a distinctive subset of malignant tumors retaining most of the structural, phenotypic and functional characteristics of normal endocrine cells of the digestive tract, which belong to the diffuse neuroendocrine cell sys- 
tem. Although GEP NETs are rare, their incidence and, above all, their prevalence are increasing [1]. The new WHO classification 2010 classifies GEP NETs into three main categories: NETs G1, NETs G2 and neuroendocrine carcinomas. NETs G1 and G2 are morphologically well differentiated tumors with respectively, low and intermediate proliferative capacities. Neuroendocrine carcinomas are defined as poorly differentiated tumors, with high proliferative capacities; the recent WHO classification now recognizes two types of GEP neuroendocrine carcinomas: the small cell and the large cell types [2].

GEP NETs raise difficult therapeutic problems. Surgical resection is the only curative treatment of localized primary NETs G1 and G2. Metastatic disease requires systemic treatments: the range of therapeutic options for well-differentiated NETs has recently dramatically increased, in particular with the emergence of targeted therapies, such as everolimus and sunitinib, which significantly improved progression-free survival in some subsets of NETs, such as pancreatic NETs [3, 4]. By contrast, there is no recent progress in the treatment of poorly differentiated neuroendocrine carcinomas (PDNECs). The standard option for small cell neuroendocrine carcinomas remains a chemotherapy based on the combination of cisplatin and etoposide $[5,6]$. However, the median survival remains very low, recurrence is constant and there is no consensus about the best strategy to adopt when a second line of treatment is required and feasible. Moreover, there is no consensus treatment for the rare and recently individualized large cell GEP neuroendocrine carcinomas.

It is therefore important to explore new therapeutic strategies for patients with GEP PDNECs. Very interestingly, Lindholm et al. [7] recently reported a response to temozolomide and bevacizumab in a patient with PDNEC, progressive on standard treatment by cisplatin and etoposide. This result not only supports the interest of the combination of temozolomide and bevacizumab as a therapeutic option, but also suggests that targeted therapies must not be neglected in PDNECs.

Everolimus is a mammalian target of rapamycin (mTOR) inhibitor which inhibits the mTOR complex 1 (mTORC1) and the phosphorylation of its downstream effectors: p70S6kinase (p70S6K) and 4E-BP1. The mTOR pathway is a major mechanism of cellular growth and homeostasis. Its regulation is frequently altered in a large variety of tumors. mTOR thus appeared as a potential target for anticancer therapy, and its inhibition with everolimus has been approved for renal cell carcinoma treatment [8]. Several recent reports support a role for mTOR pathway in GEP NETs. In a large cohort of 99 GEP NETs,
Kasajima et al. [9] reported variations in mTOR expression and activity pattern related to tumor location and metastatic status. Downregulation or mutations of PTEN and TSC2, two key inhibitors of the mTOR pathway have been described in pancreatic NETs [10, 11], whereas rapamycin sensitivity was related to PI3kinase and PTEN mutations, as well as to the phosphorylation level of Akt [12]. Furthermore, in well-differentiated GEP NETs, two recent clinical trials reported extremely promising results with everolimus combined or not with octreotide $[3,13]$. To date, since patients with PDNECs have been excluded from clinical trials, the effects of mTOR inhibitors have not been evaluated in these aggressive tumors. Interestingly, two recent studies have shown that high levels of phospho-mTOR are frequently detected in PDNECs [14, 15], which may lend some support to the therapeutic targeting of mTOR pathway in this tumor subset.

The aim of the present study was to assess the antitumor effect of everolimus in preclinical models of PDNECs, based on two neoplastic neuroendocrine cell lines xenografted in nude mice. We reported that everolimus exerted a strong antitumoral effect in these models, making mTOR inhibitors good candidates as therapeutic options alternative or additional to the currently recognized standard options.

\section{Material and Methods}

Human Tissue Samples

Tissue samples of GEP PDNECs were obtained from the collection of digestive NETs housed in the tumor tissue bank 'Tumorothèque des Hospices Civils de Lyon' (Lyon, France). Six cases were retrieved; their clinical and pathological characteristics are summarized in table 1 .

Cell Lines

The STC-1 cell line, a gift of G. Rindi (Department of Pathology and Laboratory Medicine, Roma, Italy), and the GluTag cell line, a gift of D. Drucker (Department of Medicine, Mt Sinai Hospital, Toronto, Ont., Canada), are derived from endocrine intestinal tumors developed in transgenic mice. Both cell lines retain the capacity to synthesize end secrete several neuroendocrine peptides $[16,17]$. Cells were routinely cultured in DMEM supplemented with 5 or $10 \%$ fetal calf serum (FCS) (for, respectively, STC-1 or GluTag cells), $2 \mathrm{~mm}$ glutamine and antibiotics (100 UI/ml penicillin, $100 \mu \mathrm{g} / \mathrm{ml}$ streptomycin).

\section{Protein Analysis}

Cells were seeded at a density of $0.15 \cdot 10^{6}$ cells per well in 6-well plates and maintained $72 \mathrm{~h}$ under normal culture conditions. The medium was then replaced by $0.05 \%$ FCS-containing DMEM medium for $24 \mathrm{~h}$. The growth factor IGF-1 (PeproTech, Rocky Hill, N.J., USA) and the mTOR signaling inhibitor everolimus (Selleck 
Table 1. Clinical and pathological features in human patients

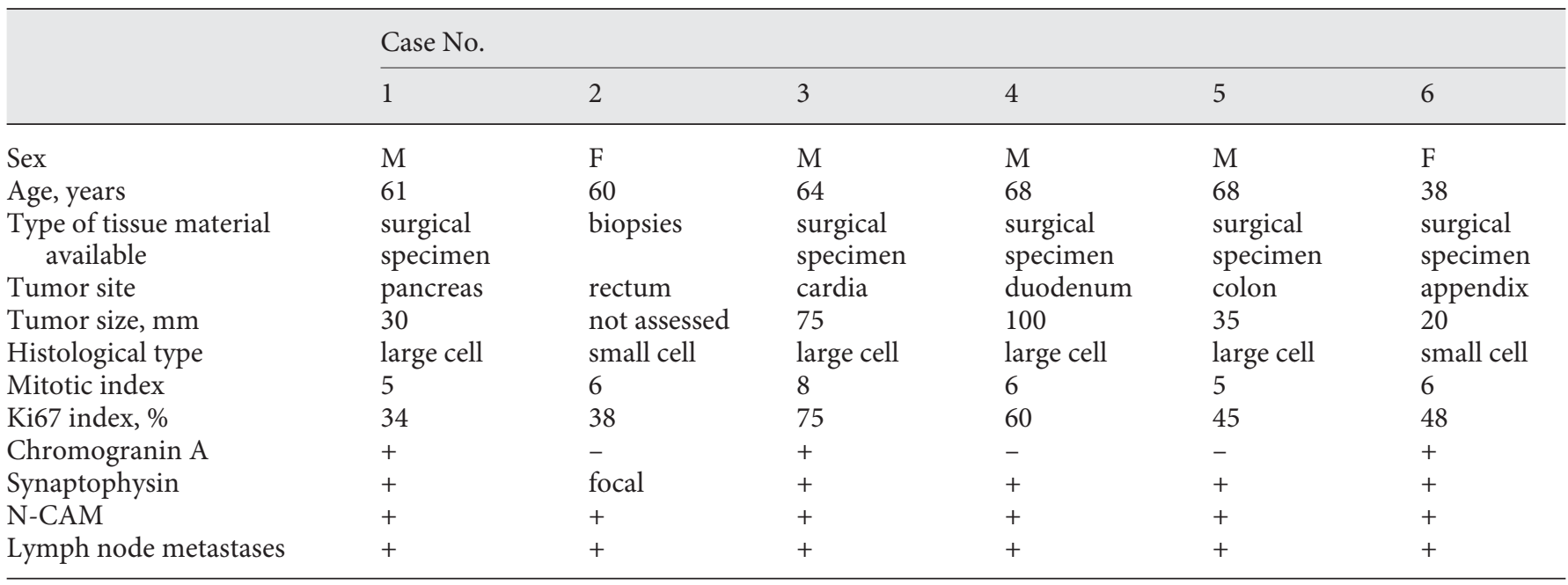

Chemicals, Houston, Tex., USA) were added for 24 h. Cells were then washed with cold PBS and lysed in cold solubilization buffer ( $\mathrm{pH}$ 8) containing $150 \mathrm{~mm} \mathrm{NaCl}, 50 \mathrm{~mm}$ Tris-base, $2 \mathrm{~mm}$ EDTA, $0.5 \%$ deoxycholate, $0.1 \%$ SDS, $1 \%$ NP40, 2 mM Orthovanadate, and $20 \mathrm{~mm} \mathrm{NaF}$. Cell lysates were centrifuged at 13,000 rpm for 15 $\min$ at $4^{\circ} \mathrm{C}$ and the supernatant was stored at $-80^{\circ} \mathrm{C}$. Protein yield was quantified using the Bradford protein assay kit. Total protein lysates $(20 \mu \mathrm{g})$ were separated by electrophoresis on a $7.5 \%$ SDSPAGE gel and transferred to a PVDF membrane (Millipore, Billerica, Mass., USA). Saturation was performed in a $0.1 \%$ Tween 20 Tris-buffered saline solution containing 5\% non-fat dry milk for $1 \mathrm{~h}$. The membranes were hybridized with primary antibodies overnight at $4^{\circ} \mathrm{C}$, washed and incubated with the corresponding immunoperoxidase-conjugated secondary antibody (Jackson ImmunoResearch Laboratories; Beckman Coulter France, Roissy, France) for $1 \mathrm{~h}$ at room temperature. Immunodetection was performed using electrochemiluminescence (ECL Western Blotting Detection System; Covalab, Villeurbanne, France) and the ChemiDoc XR5 machine (Bio-Rad, Marnes la Coquette, France). Crossdetection between phosphorylated and total forms of the proteins of interest was avoided by stripping the membranes. Antibodies against phospho-mTOR ${ }^{\text {ser2448 }}$ (No. 2971), mTOR (No. 2972), phospho-p70S6K ${ }^{\text {thr389 }}$ (No. 9234) and p70S6K (No. 9202) were purchased from Cell Signaling Technology (Beverly, Mass., USA). Antibodies against phospho-4E-BP1 and 4E-BP1 were from Epitomics (Burlingame, Calif., USA), Antibody against $\alpha$-tubulin was from Sigma-Aldrich (St. Louis, Mo., USA).

\section{In vivo Studies}

Four-week-old female Swiss nu/nu mice were obtained from Charles River Laboratories (L'Arbresle, France). The animals were maintained in a sterile environment and treated in accordance with ethical recommendations and guidelines of the Animal Welfare Committee of University Lyon 1. Animals were anesthetized prior to all surgical procedures. After surgery, animals were allowed to recover in a sterile atmosphere and were fed ad libitum with a sterile diet.
The xenografting procedure was as previously described [18, 19]. Briefly, $50 \mu \mathrm{l}$ of a solution containing tumor cells adjusted to a final concentration of $5 \cdot 10^{7}$ cells $/ \mathrm{ml}$ were injected into the spleen, from where they disseminated into the liver through the portal vein to form intrahepatic tumor nodules. Three days after cell injection, animals were randomized into treatment and control groups and received everolimus intraperitoneally at a dose of 1.5 $\mathrm{mg} / \mathrm{kg} /$ day or vehicle only, until the end of the experiment. Animals were weighted twice a week, and sacrificed at day 28; livers were excised and prepared for histological analysis. A total of 48 mice were xenografted with STC- 1 cells ( 24 controls, 24 treated) and 20 mice with GluTag cells (10 controls, 10 treated).

\section{Histologic Analysis and Morphometry}

Tissue samples of all animals were fixed in $10 \%$ buffered formalin and embedded in paraffin. For histologic examination, 4 - $\mu \mathrm{m}$-thick sections were prepared according to conventional procedures, stained with hematoxylin-phloxin-safran and observed with a light microscope. The amount of intrahepatic tumor tissue was evaluated by morphometry (Histolab; Microvision Instruments, Evry, France). The total surface occupied by tumor tissue was defined as the sum of each individual lesion and was expressed as a percentage of the total surface of the corresponding reference tissue section. The same procedure was followed to determine the number of nodules and the mean nodule surface.

\section{Immunohistochemical Analysis}

Immunohistochemistry was performed using a panel of primary antibodies against phospho-mTOR ${ }^{\text {ser2448 }}$ (Abcam, Cambridge, UK), phospho-p70S6K (Santa-Cruz Biotechnology, Santa Cruz, Calif., USA), phospho-4E-BP1 (Epitomics, Burlingame, Calif., USA), Ki67 (clone TEC3, Dako, Glostrup, Denmark) and active caspase 3 (R\&D Systems, Lille, France).

Antigen retrieval was performed by incubating sections for 35 min in a citrate buffer $(\mathrm{pH} 6)$ preheated at $98^{\circ} \mathrm{C}$. A standard horseradish peroxidase staining procedure was followed using an appropriate biotinylated antibody and the EnVision ${ }^{\mathrm{TM}}$ detection kit 


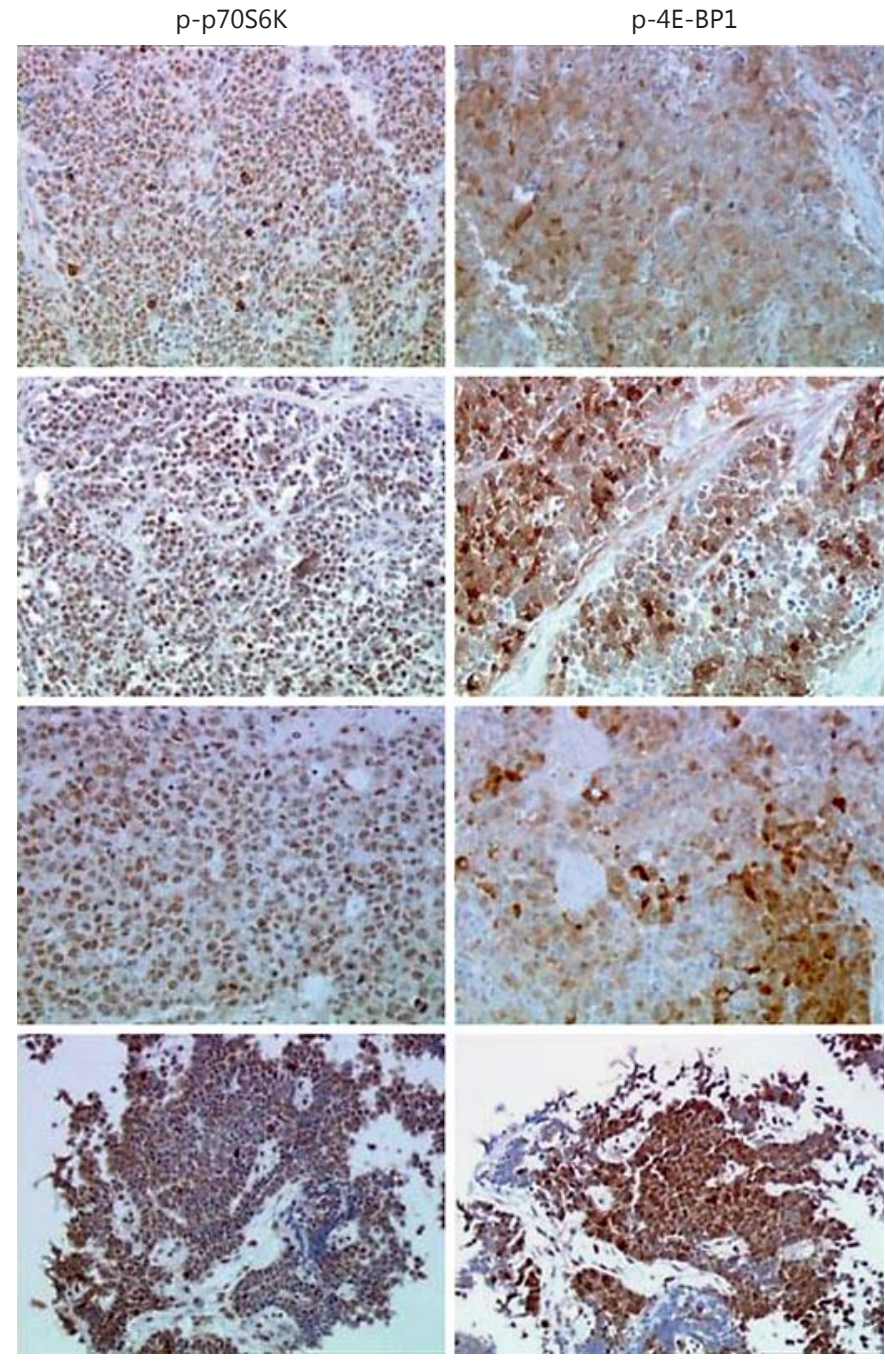

Fig. 1. p-p70S6K and p-4E-BP1 expression patterns in 4 cases of PDNECs. Immunoperoxidase. $\times 120$.

(Dako, Trappes, France). All sections were counterstained with Meyer's hematoxylin. Negative controls were achieved by omission of the primary antibody.

The proliferation index of tumor cells was determined by counting the number of nuclei positive for Ki67 antigen in 1,000 cells (at least 200 cells per nodule); the result was expressed as the percentage of labeled cells. The same method was applied for evaluating the percentage of cells expressing active caspase 3 .

\section{Statistical Analysis}

Statistical analyses were carried out with StatView (SAS Institute). Differences in viability and morphometric data were investigated by using the Mann-Whitney U test. $\mathrm{p}<0.05$ was considered statistically significant. The results are shown as the mean \pm SEM.

\section{Results}

\section{Expression of mTOR Signaling Pathway in Human} GEP PDNECs

In the 6 cases of GEP PDNECs retrieved from our collection (table 1), we evaluated the apparent expression levels of the two major effectors of mTOR: phospho-p70S6Kand phospho-4E-BP1 by immunohistochemistry. In all tumors examined, including 2 cases of small cell PDNECs and 4 cases of large cell PDNECs, the majority of neoplastic cells exhibited a strong expression of the two proteins. As illustrated in figure 1, phosphorylated p70S6K was detected in the nucleus of tumor cells, whereas the distribution of phosphorylated 4E-BP1 was nuclear and cytoplasmic.

\section{STC-1 and GluTag Cell Lines Mimic PDNECs in vivo}

Among the various neuroendocrine cell lines used in the laboratory, we selected STC-1 and GluTag because the tumors derived from these cells xenografted to nude mice closely resemble human PDNECs. As shown in figure $2 \mathrm{a}$, intrahepatic nodules derived from xenografted STC-1 and GluTag were formed by neoplastic cells with neuroendocrine morphology. Tumor nodules were made of solid sheets of neoplastic cells interspersed with small cystic spaces filled with red blood cells. Neoplastic cells were small- to medium-sized, with a high nucleo-cytoplasmic ratio, their cytoplasm was basophilic, and the nuclei were large with a granular, finely dispersed chromatin sometimes containing one or several small nucleoli. The overall architecture and cell morphology were therefore reminiscent of those observed in human GEP PDNECs.

We analyzed by immunohistochemistry the expression of phosphorylated forms of mTOR, 4E-BP1 and p70S6K in the intrahepatic nodules of xenografted mice. A strong expression of phosphorylated mTOR, p70S6K and 4EBP1 was detected in both STC-1- and GluTag-derived intrahepatic nodules (fig. $2 \mathrm{~b}$ ). These results showed that the expression profile of the major effectors of the mTOR pathway in our experimental tumors was comparable to that observed in human GEP PDNECs. Furthermore, the Ki-67 index was $52.0 \pm 4.2$ and $30.5 \pm 2.4 \%$ in STC- 1 - and GluTag-derived intrahepatic nodules, respectively, which is in the range usually observed in PDNECs.

These morphological and immunophenotypic observations confirmed that STC-1- and GluTag-derived tumors, despite some differences, such as the capacities of hormone secretion $[16,17]$, could be considered representative of human high grade GEP neuroendocrine neoplasms because of their morphology, functional properties, high proliferative capacities and rapid growth. 
Fig. 2. STC-1 and GluTag cell lines mimic PDNECs. a Intrahepatic nodules induced after STC-1 or GluTag xenografts were closely related to human PDNEC. b STC1- and GluTag-induced intrahepatic nodules strongly expressed phosphorylated forms of mTOR, p70S6K and 4E-BP1. $\times 20$. a
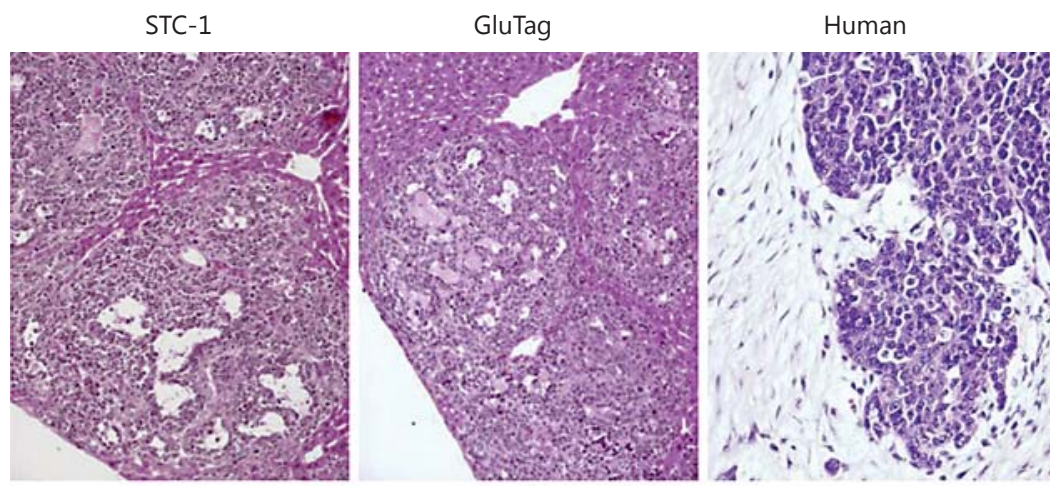

b
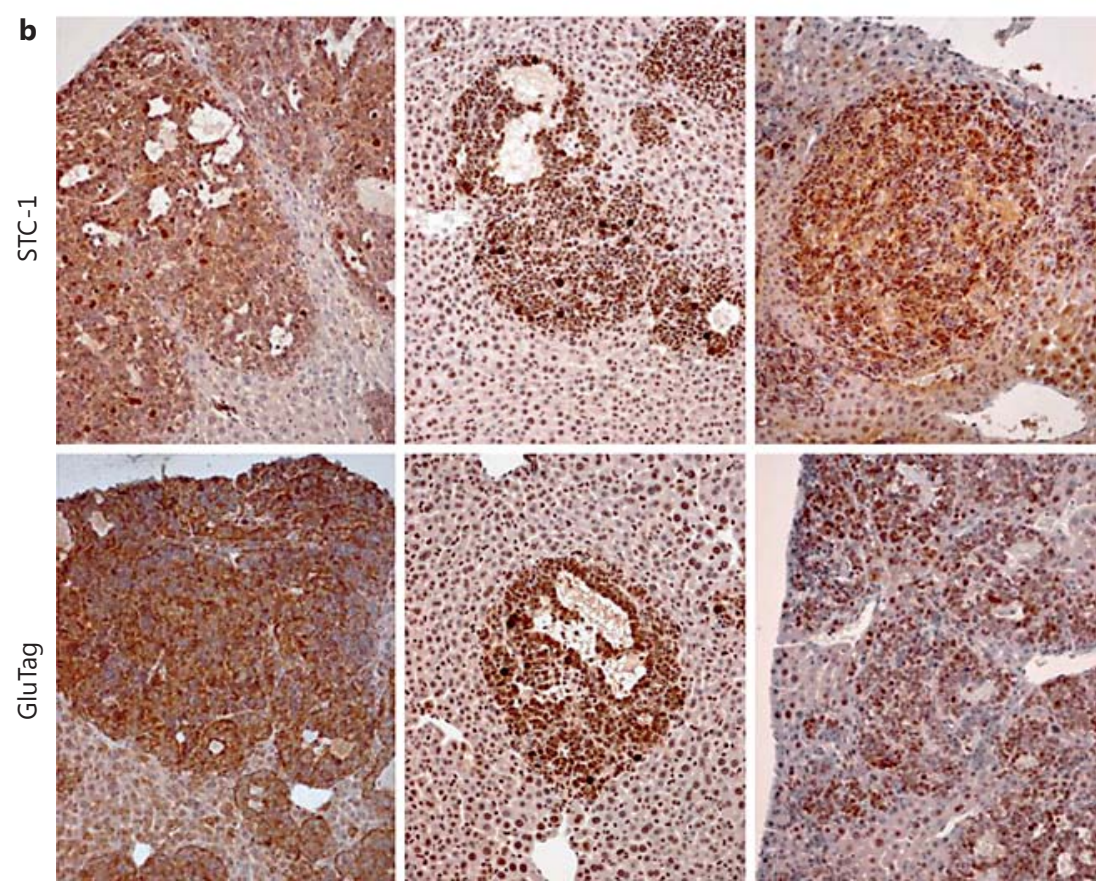

p-mTOR

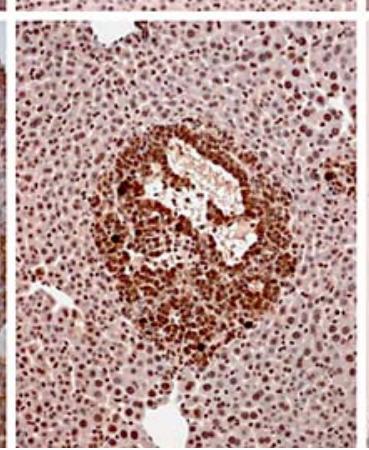

p-p70S6K

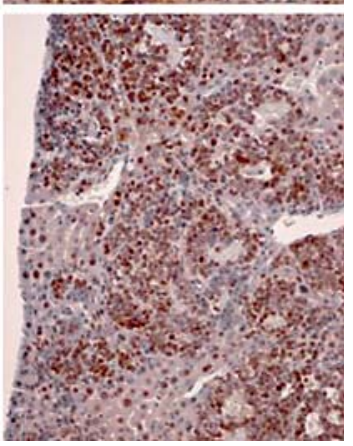

$p-4 E-B P 1$
Effects of Everolimus on the mTOR Signaling Pathway in vitro

We then verified that both cell lines constitutively express a functional mTOR pathway in vitro. The expression of total and phosphorylated forms of mTOR, p70S6K and $4 \mathrm{E}-\mathrm{BP} 1$ was assessed by Western blotting after protein extraction on cells maintained in normal culture conditions. The proteins mTOR, p70S6K and 4EB-P1 were expressed and furthermore, highly phosphorylated in both STC-1 and GluTag cell lines (fig. 3, lane 1).

We then examined whether everolimus can inhibit the mTOR signaling pathway in STC-1 and GluTag cells. To address this question, cells were treated with 3 $\mathrm{nM}$ exogenous IGF-1 to mimic the microenvironment conditions of the tumors. As shown in figure 3, lane 2, IGF-1 was able to increase the phosphorylation of mTOR, p70S6K and 4E-BP1. Everolimus (11 nM) reduced IGF-1-induced phosphorylation of mTOR to the basal level, whereas it induced complete abrogation of p70S6K and 4E-BP1 phosphorylation in both cell lines (fig. 3, lane 3). These results showed that everolimus totally inhibited the action of the effectors of mTOR in STC-1 and GluTag cells. 


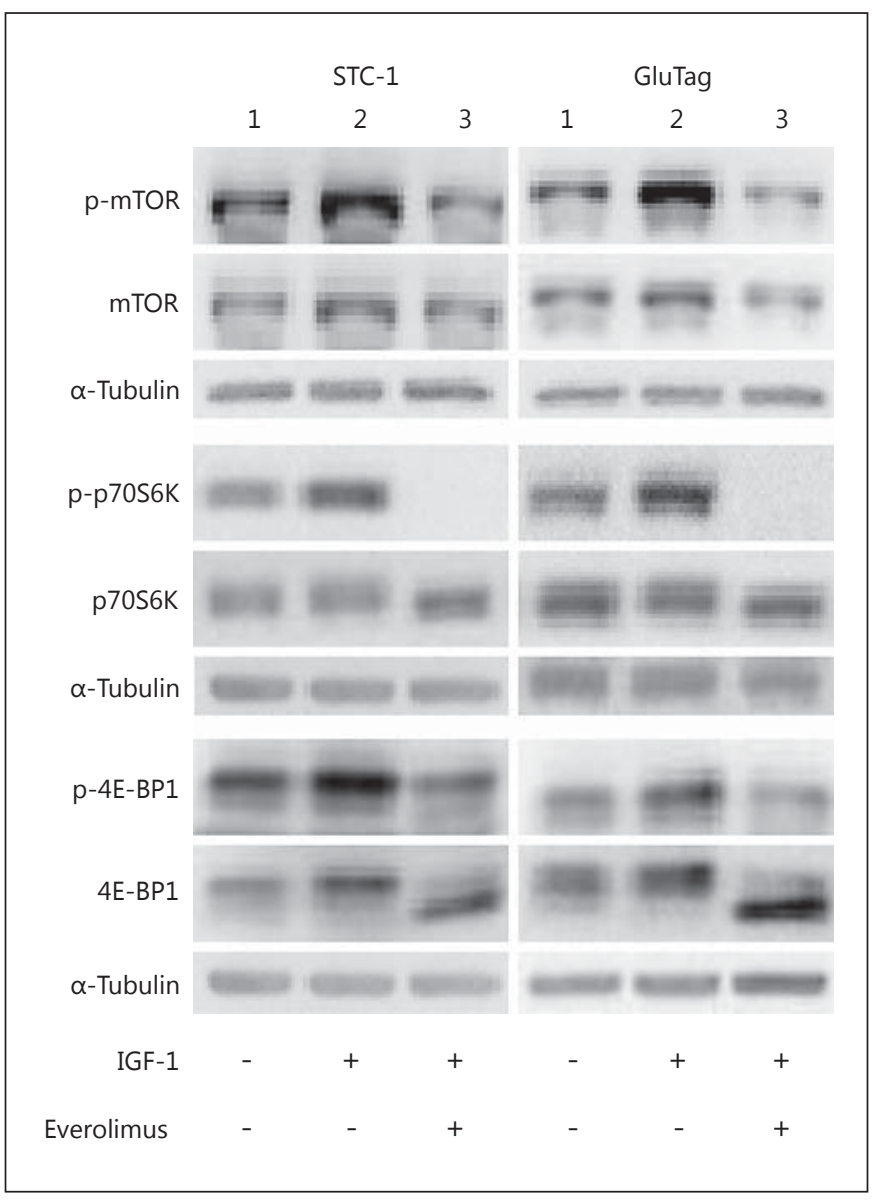

Fig. 3. Effect of everolimus on the mTOR pathway in STC-1 and GluTag cell lines by Western blot analysis after protein extraction. Lane 1: STC-1 and GluTag cells expressed high levels of mTOR, p-mTOR, p70S6K, p-p70S6K, 4E-BP1 and p-4EB-P1 in normal culture conditions. Lanes 2 and 3: the mTOR pathway was stimulated with IGF-1 (3 nM) and the effect of everolimus (11 nM) was assessed in the presence of IGF-1 at $24 \mathrm{~h}$. IGF-1 promoted the phosphorylation of mTOR, p70S6K and 4E-BP1 in both STC-1 and GLUTag cells, whereas everolimus reversed the IGF-1-induced phosphorylation. Representative of at least three independent experiments.

\section{Effects of Everolimus on Tumor Development in}

\section{Xenograft Models}

The effect of everolimus on the development of STC1- and GluTag-derived intrahepatic tumor nodules was assessed in the experimental model of intrahepatic dissemination after intrasplenic injection of tumor cells [18, 19]. Everolimus treatment strongly inhibited tumor development in vivo. In STC-1-xenografted mice, the total tumor tissue surface evaluated to $14.84 \pm 2.06 \%$ in control animals was significantly reduced to $2.51 \pm 0.6 \%$ in treat- ed animals $(\mathrm{p}<0.05)$. Similar results were obtained in GluTag-xenografted mice: the total tumor surface was significantly decreased from $21.76 \pm 3.88 \%$ in control animals to $6.05 \pm 1.84 \%$ in treated animals ( $<<0.05$ ) (fig. 4). As shown in figure 4 , everolimus-induced reduction of tumor surface was the result of a decrease of the number of tumor nodules as well as their mean surface in both STC-1- and GluTag-xenografted mice.

Ki67 index determined in STC-1-derived intrahepatic nodules was $52.0 \pm 4.2 \%$ in control animals as compared to $41.33 \pm 2.56 \%$ in treated animals. Similar results were obtained in GluTag-derived intrahepatic nodules where Ki67 index was $30.5 \pm 2.4 \%$ in control animals as compared to $20.44 \pm 0.95 \%$ in treated animals. The differences were statistically significant $(\mathrm{p}<0.05)$. These results suggested that the reduction in tumor mass observed under everolimus was, at least in part, due to an in vivo antiproliferative effect of the drug. In contrast, no difference was observed in the percentage of cells expressing active caspase 3 between control and treated animals.

Interestingly, body-weight curves indicated a significant stabilization of the weight of treated animals, whereas control animals lost weight from day 18 in both experiments (fig. $4 \mathrm{c}, \mathrm{d}$ ). This result suggests that everolimus treatment may be able to improve the clinical status of the animals xenografted with either STC-1 or GluTag cells.

\section{Antitumor Effect of Everolimus Was Correlated to the Inhibition of mTOR Signaling}

To assess whether the antitumor property of everolimus in vivo was associated with the inhibition of the mTOR signaling pathway, we analyzed by immunohistochemistry the expression of phosphorylated forms of mTOR, 4E-BP1 and p70S6K in the intrahepatic nodules of xenografted mice. While the expression of phosphomTOR remained unchanged in treated mice, the apparent expression levels of phospho-4E-BP1 and phospho-p70-S6K were greatly reduced in everolimus-treated animals bearing both STC-1- and GluTag-derived tumors (fig. 5).

\section{Discussion}

PDNECs amount up to only 5-10\% of GEP NETs and, while they may occur anywhere in the gastrointestinal tract, they predominate in the hindgut. The recent WHO classification recognized two distinct morphological subtypes: the small cell type and the large cell type. Despite the current treatments, based on the combination etopo- 

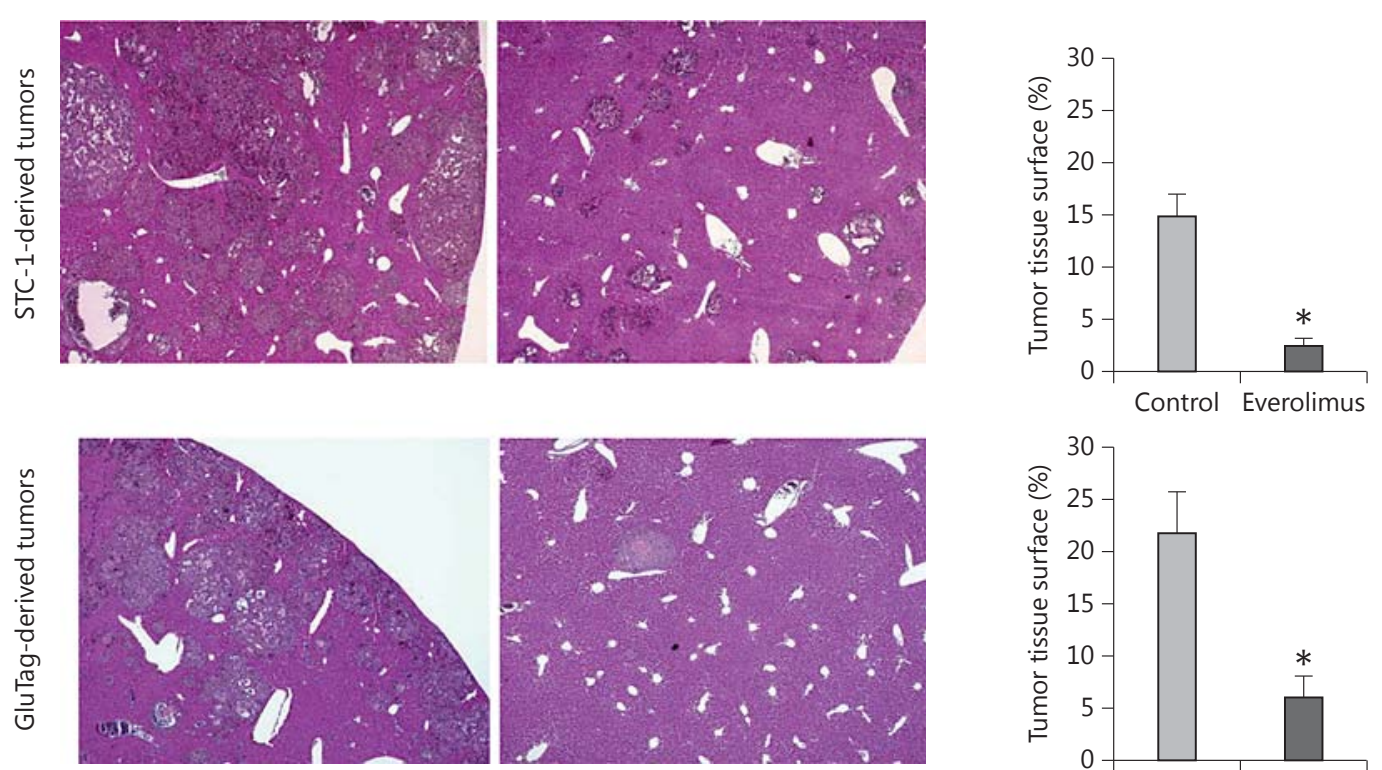

a

Control

Everolimus
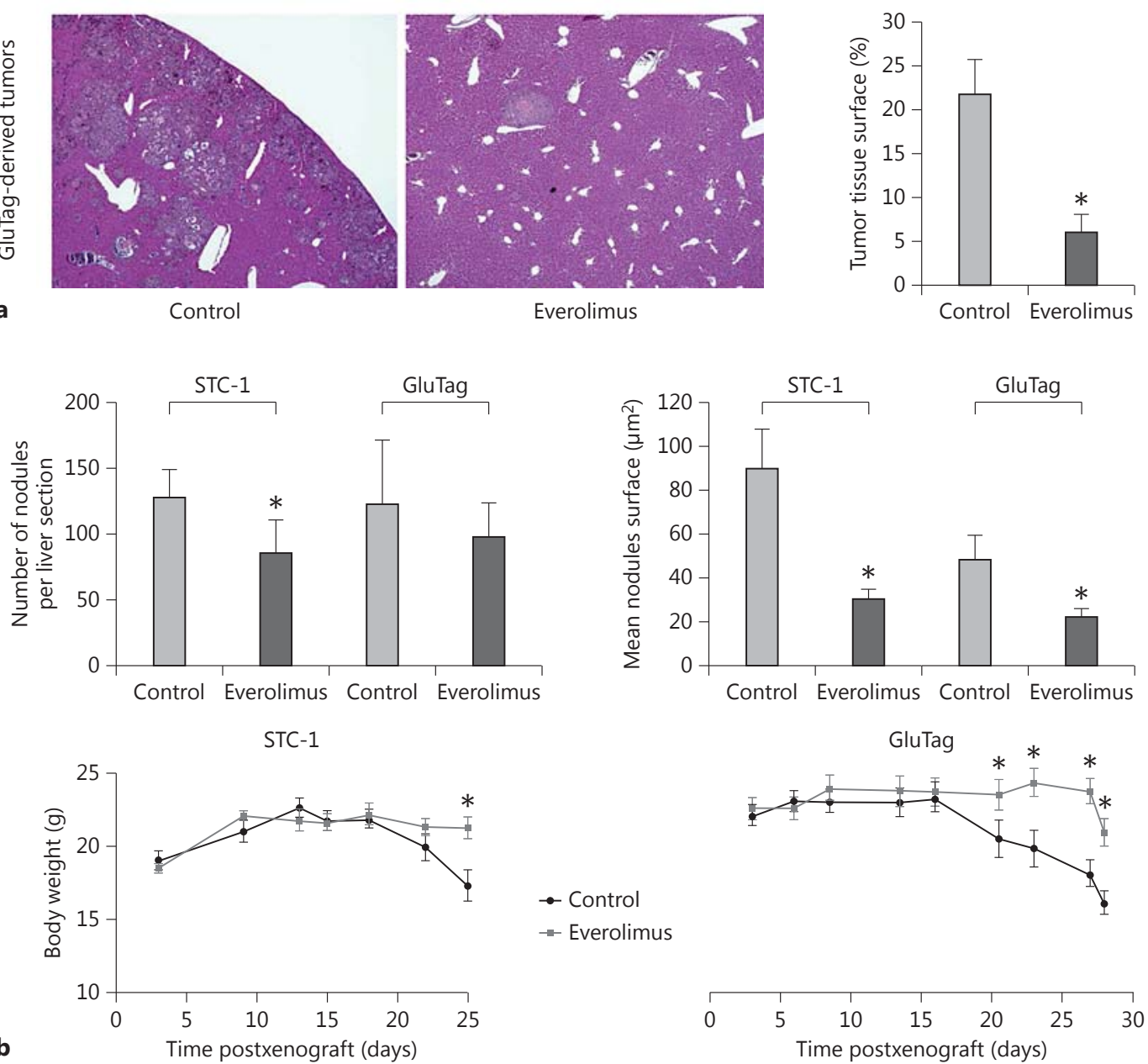

$\rightarrow-$ Control

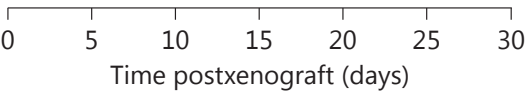

Fig. 4. In vivo effects of everolimus in a xenograft model. Everolimus ( $1.5 \mathrm{mg} / \mathrm{kg} /$ day) or vehicle was administrated to mice during 25-28 days following intrasplenic graft. a Histologic and morphometric analyses of intrahepatic tumors after STC-1 and GLUTag xenografts. Control liver displayed large intrahepatic nodules while only few small nodules invaded the liver of treated mice. HPS staining. $\times 4$. The total tumor tissue surface was significantly reduced upon everolimus treatment $(* \mathrm{p}<0.05)$. $\mathbf{b}$ Everolimus reduced the number of intrahepatic nodules as well as the surface of the nodules $(* \mathrm{p}<0.05)$. Everolimus treatment delayed the loss of weight observed in control mice from day 18, either in STC-1- or GluTag-xenografted mice. 


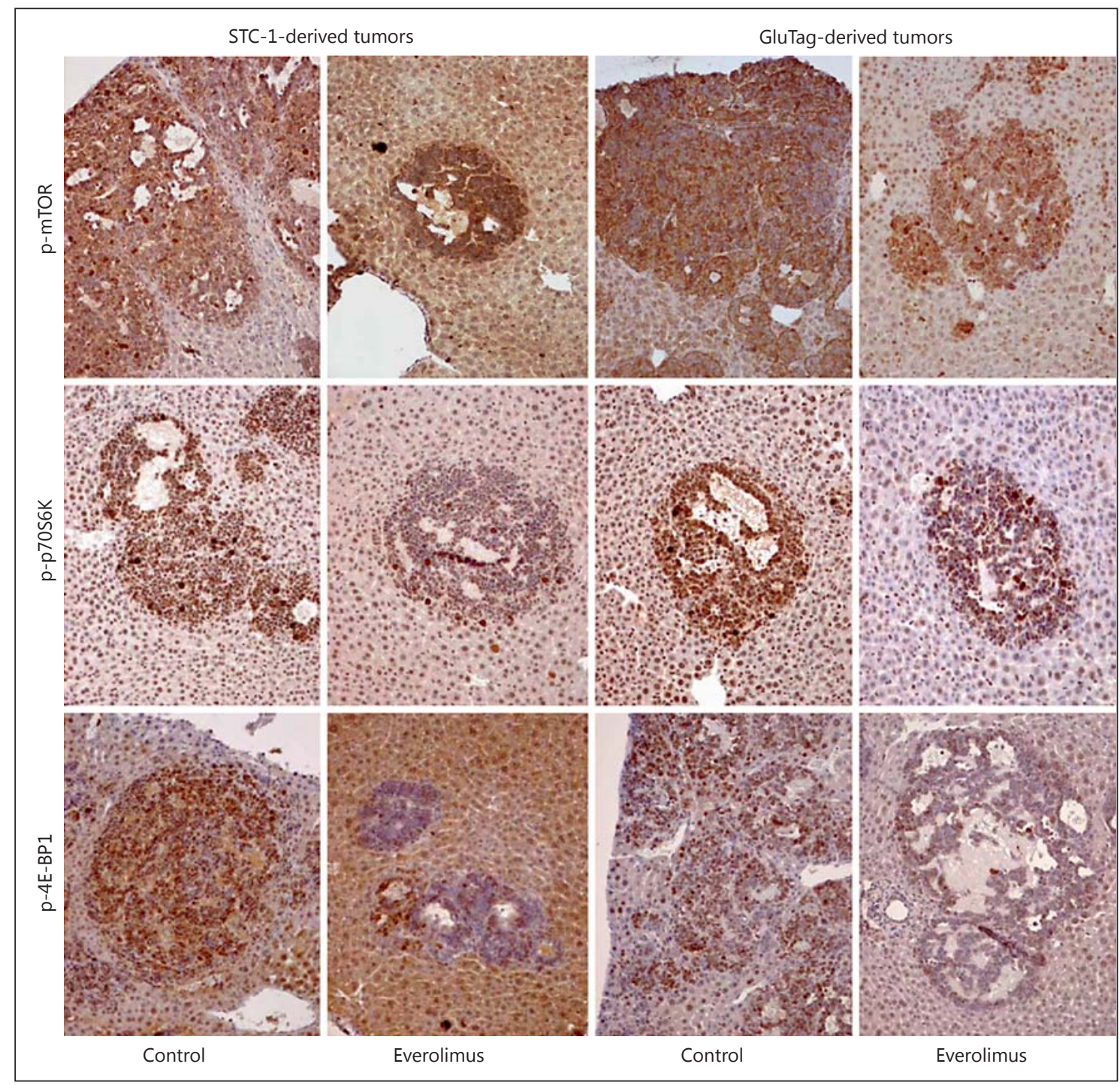

Fig. 5. Effect of everolimus on the expression pattern of the mTOR pathway in STC-1- and GluTag-derived intrahepatic tumors: whereas the expression of p-mTOR remained stable, p-p70S6K and p-4EB-P1 expression was reduced by everolimus treatment. $\times 20$.

side-cisplatin, the prognosis of both subtypes is poor, with median survival durations in patients with localized, regional and distant disease of 34, 14 and 5 months, respectively [1]. It is therefore important to search for new therapeutic strategies in order to improve the efficacy of first- or second-line therapies for these very aggressive tumors. In this context, Lindholm et al. [7] described a dramatic response to a combination of temozolomide, an alkylating agent, and bevacizumab, a monoclonal antibody targeting tumor angiogenesis, after failure of cisplatin and etoposide. This study demonstrated the potential antitumor effect of the anti-VEGF antibody bevacizumab combined with temozolomide. Other targeted therapies have never been evaluated in PDNECs.

The rarity of these tumors has so far hampered the development of clinical trials. In this context, we designed preclinical models of PDNECs on the basis of two tumor endocrine cell lines: STC-1 and GluTag. Tumors derived from STC-1 or GluTag cells xenografted to nude mice present strong morphological similarities with human PDNECs: overall architecture, cell morphology and high proliferative capacities. Some differences must be ac- 
knowledged: STC-1 and GluTag cells retain capacities of hormone synthesis and secretion [16, 17], in contrast to most human PDNECs, and do not harbor TP53 mutations, which are frequent in PDNECs [20]. Despite these functional and molecular differences, STC-1 and GluTag can be considered as representative of high grade human neuroendocrine neoplasms because of their high proliferative capacities and rapid growth.

Among targeted therapies, the antitumor activity of everolimus, an oral inhibitor of mTOR, was recently demonstrated in well-differentiated GEP NETs: the RADIANT 3 trial reported a significant increase of progressionfree survival from 4.6 months with placebo to 11 months with everolimus in patients with advanced pancreatic NETs [3]. In patients with carcinoid syndrome, the combination of everolimus and octreotide had an almost significant effect on progression-free survival [13]. Recent observations in the literature supported a rationale to evaluate this therapy in patients with PDNECs. First of all, Shida et al. [14] compared the expression of phosphomTOR between well-differentiated and poorly differentiated neuroendocrine neoplasms. The authors observed a high expression of phospho-mTOR in 67\% of PDNECs, as compared to $27 \%$ of well-differentiated NETs and carcinomas. Secondly, Catena et al. [15] studied the expression of phospho-mTOR in a series of 36 patients diagnosed with PDNECs. A high expression of phosphomTOR was observed in $80 \%$ of these tumors. Furthermore, in a phase II study evaluating the effect of temsirolimus (another mTOR inhibitor) in advanced neuroendocrine carcinomas, higher baseline levels of phospho-mTOR were predictive of tumor response and decrease in phospho-mTOR after temsirolimus treatment was associated with increased time to progression [21].

In the present study, we also demonstrated a strong expression of phospho-mTOR and its related effectors in several cases of PDNECs obtained from our tumor collection. Moreover, STC-1 and GluTag cell lines demonstrated a high activity of the mTOR pathway in vitro, which can be easily reduced by everolimus. We thus treated STC-1 and GluTag-xenografted mice with everolimus, and evaluated the antitumor effect of this MTOR inhibitor 4 weeks later. First of all, everolimus was able to reduce the weight loss induced by growing tumors, thus improving the clinical status of the animals. We cannot definitively exclude that this effect could be mediated, at least in part, through a decrease in hormone release from neoplastic cells, either indirectly through the reduction of tumor mass, or directly through an inhibitory effect of everolimus on hormone secretion, as described in some clinical situations. This may be particularly the case for the two cell lines used in this study, since GLP-1, produced by STC-1 cells [16], and glucagon, produced by GluTag cells [17], are suspected to play a role in cancer cachexia and anorexia [22]. The differences observed between the body-weight curves of STC-1- and GluTagbearing animals may be due to a major catabolic effect of glucagon or to a major hormone production.

At the tumor level, everolimus induced a decrease of the number of nodules as well as their mean surface, resulting to a dramatic decrease of the total tumor surface. This was concomitant with a clear decrease of the phosphorylation level of the two major effectors of mTOR, p70S6K and 4E-BP1, inside the tumor nodules. Our data suggest that this important reduction in tumor mass is due to a decrease in proliferation rather to an increase in apoptosis, since we found a significant decrease in Ki67 index between control and treated animals, but no difference in the percentage of cells expressing active caspase 3 . Additional effects of everolimus treatment may be also involved, such as the antiangiogenic effect we previously observed with another mTOR inhibitor, rapamycin, in a comparable preclinical model [19].

Our results, together with those of the literature, strongly suggested that the rapid progression of PDNECs could be related to the high activity of the mTOR pathway in these tumor cells. The results obtained with preclinical models supported the potential interest of the mTOR inhibitors as effective anti-tumor agents for these highly malignant tumors. As suggested by the success of the combination bevacizumab and temozolomide [7], the use of the mTOR inhibitors should probably be considered in combination with other molecules such as chemotherapeutic agents or other targeted therapies. Indeed, a stronger efficacy should be obtained by targeting mTOR pathway at several levels, such as PI3kinase and mTOR levels, by using new inhibitors targeting both complexes mTORC1 and mTORC2, or by targeting several pathway simultaneously (mTOR and MAPkinase pathways) [23, 24]. If further clinical studies are now needed, our data suggest that mTOR inhibition could be considered a therapeutic option for high grade GEP NETs.

\section{Acknowledgements}

The authors thank Nicolas Gadot and Armelle Paquet from the Anipath platform (Université de Lyon) for their assistance in histologic and morphometric analyses.

This study was supported by a grant from the Comité de la Drôme de la Liguecontre le Cancer (C.R.). 


\section{References}

1 Yao JC, Hassan M, Phan A, Dagohoy C, Leary C, Mares JE, Abdalla EK, Fleming JB, Vauthey J-N, Rashid A, Evans DB: One hundred years after 'carcinoid': epidemiology of and prognostic factors for neuroendocrine tumors in 35,825 cases in the United States. J Clin Oncol 2008;26:3063-3072.

2 Rindi G, Klimstra DS, Arnold R, Klöppel G, Bosman FT, Komminoth P, Perren A. Nomenclature and classification of neuroendocrine neoplasms of the digestive system; in Bosman FT, Carneiro F, Hruban RH, Theise ND (eds): WHO Classification of Tumours of the Digestive System. Lyon, IARC, 2012, pp 13-14.

-3 Yao JC, Shah MH, Ito T, Bohas CL, Wolin EM, Van Cutsem E, Hobday TJ, Okusaka T, Capdevila J, de Vries EGE, Tomassetti P, Pavel ME, Hoosen S, Haas T, Lincy J, Lebwohl D, Öberg K: Everolimus for advanced pancreatic neuroendocrine tumors. N Engl J Med 2011; 364:514-523.

4 Raymond E, Dahan L, Raoul J-L, Bang Y-J, Borbath I, Lombard-Bohas C, Valle J, Metrakos P, Smith D, Vinik A, Chen J-S, Hörsch D, Hammel P, Wiedenmann B, Van Cutsem E, Patyna S, Lu DR, Blanckmeister C, Chao R, Ruszniewski P: Sunitinib malate for the treatment of pancreatic neuroendocrine tumors. N Engl J Med 2011;364:501-513.

$\checkmark 5$ Moertel CG, Kvols LK, O’Connell MJ, Rubin $\mathrm{J}$ : Treatment of neuroendocrine carcinomas with combined etoposide and cisplatin. Evidence of major therapeutic activity in the anaplastic variants of these neoplasms. Cancer 1991;68:227-232.

-6 Mitry E, Baudin E, Ducreux M, Sabourin JC, Rufié P, Aparicio T, Aparicio T, Lasser P, Elias D, Duvillard P, Schlumberger M, Rougier P: Treatment of poorly differentiated neuroendocrine tumours with etoposide and cisplatin. Br J Cancer 1999;81:1351-1355.

7 Lindholm DP, Eriksson B, Granberg D: Response to temozolomide and bevacizumab in a patient with poorly differentiated neuroendocrine carcinoma. Med Oncol 2012;29:301303.

8 Motzer RJ, Escudier B, Oudard S, Hutson TE, Porta C, Bracarda S, Grünwald V, Thompson JA, Figlin RA, Hollaender N, Urbanowitz G, Berg WJ, Kay A, Lebwohl D, Ravaud A: Efficacy of everolimus in advanced renal cell carcinoma: a double-blind, randomised, placebo-controlled phase III trial. Lancet 2008;372: 449-456.
-9 Kasajima A, Pavel M, Darb-Esfahani S, Noske A, Stenzinger A, Sasano H, Dietel M, Denkert C, Röcken C, Wiedenmann B, Weichert W: mTOR expression and activity patterns in gastroenteropancreatic neuroendocrine tumours. Endocr Relat Cancer 2011;18:181192.

10 Missiaglia E, Dalai I, Barbi S, Beghelli S, Falconi M, della Peruta M, Piemonti L, Capurso G, Di Florio A, delle Fave G, Pederzoli P, Croce CM, Scarpa A: Pancreatic endocrine tumors: expression profiling evidences a role for AKT-mTOR pathway. J Clin Oncol 2010; 28:245-255.

11 Jiao Y, Shi C, Edil BH, de Wilde RF, Klimstra DS, Maitra A, Schulick RD, Tang LH, Wolfgang CL, Choti MA, Velculescu VE, Diaz LA Jr, Vogelstein B, Kinzler KW, Hruban RH, Papadopoulos N: DAXX/ATRX, MEN1, and mTOR pathway genes are frequently altered in pancreatic neuroendocrine tumors. Science 2011;331:1199-1203.

12 Meric-Bernstam F, Akcakanat A, Chen H, Do K-A, Sangai T, Adkins F, Gonzalez-Angulo AM, Rashid A, Crosby K, Dong M, Phan AT, Wolff RA, Gupta S, Mills GB, Yao J: PIK3CA/ PTEN mutations and Akt activation as markers of sensitivity to allosteric mTOR inhibitors. Clin Cancer Res 2012;18:1777-1789.

13 Pavel ME, Hainsworth JD, Baudin E, Peeters M, Hörsch D, Winkler RE, Klimovsky J, Lebwohl D, Jehl V, Wolin EM, Oberg K, Van Cutsem E, Yao JC: Everolimus plus octreotide long-acting repeatable for the treatment of advanced neuroendocrine tumours associated with carcinoid syndrome (RADIANT-2): a randomised, placebo-controlled, phase 3 study. Lancet 2011;378:2005-2012.

14 Shida T, Kishimoto T, Furuya M, Nikaido T, Koda K, Takano S, Kimura F, Shimizu H, Yoshidome H, Ohtsuka M, Tanizawa T, Nakatani Y, Miyazaki M: Expression of an activated mammalian target of rapamycin (mTOR) in gastroenteropancreatic neuroendocrine tumors. Cancer Chemother Pharmacol 2010; 65:889-893.
15 Catena L, Bajetta E, Milione M, Ducceschi M, Valente M, Dominoni F, Colonna V: Mammalian target of rapamycin expression in poorly differentiated endocrine carcinoma: clinical and therapeutic future challenges. Target Oncol 2011;6:65-68.

16 Rindi G, Grant SG, Yiangou Y, Ghatei MA, Bloom SR, Bautch VL, Solcia E, Polak JM: Development of neuroendocrine tumors in the gastrointestinal tract of transgenic mice. Heterogeneity of hormone expression. Am J Pathol 1990;136:1349-1363.

17 Drucker DJ, Jin T, Asa SL, Young TA, Brubaker PL: Activation of proglucagon gene transcription by protein kinase-A in a novel mouse enteroendocrine cell line. Mol Endocrinol 1994;8:1646-1655.

18 Pourreyron C, Poncet G, Roche C, Gouysse G, Nejjari M, Walter T, Villaume K, Jacquier M-F, Bernard C, Dumortier J, Chayvialle J-A, Bachelot T, Scoazec J-Y: The role of angiogenesis in endocrine liver metastases: an experimental study. J Surg Res 2008;144:64-73.

19 Couderc C, Poncet G, Villaume K, Blanc M, Gadot N, Walter T, Lepinasse F, Hervieu V, Cordier-Bussat M, Scoazec J-Y, Roche C: Targeting the $\mathrm{PI} 3 \mathrm{~K} / \mathrm{m}$ TOR pathway in murine endocrine cell lines: in vitro and in vivo effects on tumor cell growth. Am J Pathol 2011;178: 336-344.

20 Rindi G, Bordi C: Endocrine tumours of the gastrointestinal tract: aetiology, molecular pathogenesis and genetics. Best Pract Res Clin Gastroenterol 2005;19:519-534.

21 Duran I, Kortmansky J, Singh D, Hirte H, Kocha W, Goss G, Le L, Oza A, Nicklee T, Ho J, Birle D, Pond GR, Arboine D, Dancey J, Aviel-Ronen S, Tsao M-S, Hedley D, Siu LL: A phase II clinical and pharmacodynamic study of temsirolimus in advanced neuroendocrine carcinomas. Br J Cancer 2006;95: 1148-1154.

22 Inui A: Cancer anorexia-cachexia syndrome. Are neuropeptides the key? Cancer Res 1999; 59:4493-4501.

23 Albert S, Serova M, Dreyer C, Sablin M-P, Faivre S, Raymond E: New inhibitors of the mammalian target of rapamycin signaling pathway for cancer. Expert Opin Investig Drugs 2010;19:919-930.

24 Laplante M, Sabatini DM: mTOR signaling in growth control and disease. Cell 2012;149: 274-293. 